BJHS: Themes 1: 169-198, 2016. C British Society for the History of Science 2016. This is an Open Access article, distributed under the terms of the Creative Commons Attribution licence (http://creativecommons.org/licenses/by/4.0/), which permits unrestricted re-use, distribution, and reproduction in any medium, provided the original work is properly cited.

doi:10.1017/bjt.2016.8 First published online 23 May 2016

\title{
Studying the snow leopard: reconceptualizing conservation across the China-India border
}

\author{
MICHAEL LEWIS* AND E. ELENA SONGSTER**
}

\begin{abstract}
The snow leopard is a highly charismatic megafauna that elicits admiration, concern and donations from individuals and NGOs in the West. In its home territories, however, it is a threat to local communities' livestock and a potential source of income for its pelt and parts. Conservation and study are further challenged by its range; snow leopards traverse the borders separating China, India and ten other countries with long histories of tension with each other as well as internal political and economic struggles. This transnational animal provides an ideal case study for the consideration of transnational conservation science in the recent past.
\end{abstract}

In 2009 a group of soldiers in the Indo-Tibetan Border Police (ITBP) were doing a training exercise in Spiti, a high-altitude trans-Himalayan region of India bordering Tibet. As they passed along the narrow trails of the Himalayas, the soldiers discovered hidden cameras photographing their movements. The soldiers carefully collected the cameras, certain that they had been set by spies attempting to ascertain Indian troop movements along the border. The cameras were taken to the ITBP regional headquarters, and an investigation commenced.

An Indian graduate student was doing research on snow leopard populations in the Spiti Valley. The student had set a series of camera traps along game trails, triggered to take photographs of animals, but which would in fact photograph anything that passed by, including, inadvertently, the occasional soldier. Fortunately, the graduate student had permission to set out the camera traps, and had informed the local units of the ITBP and the local village head, and in a relatively short while, with help from the Spiti Forest Department officials and local police, the potentially tricky incident was resolved - but the lost scientific data was not so easily recovered. ${ }^{1}$

The snow leopard is challenging to study. For scientists who study snow leopards, the particularities of place are the oft unspoken and unwritten context of their work. As opposed to lab sciences, where experiments and observations can be replicated anywhere

\footnotetext{
* Environmental Studies House, Room 3, Department of Environmental Studies, Salisbury University, 1101 Camden Avenue, Salisbury, Maryland 21801, USA. Email: mllewis@salisbury.edu.

** Department of History, St Mary's College of California, 1928 Saint Mary's Road, Moraga, California 94575, USA. Email: ees4@stmarys-ca.edu.

1 Interview with Yash Veer Bhatnagar, Mysore, 18 March 2013, transcript on file with Michael Lewis.
} 
with appropriate equipment, field sciences are studies of particular places, flora and fauna - the particular case study is the necessary starting point for a general theory. To study the ecology of the Himalayas, you must start with field data from the Himalayas. While many techniques might be transferable (camera trapping of animals, or computer modelling of ecosystem interactions), they are applied in and on specific places. Snow leopards range across the world's highest and most rugged mountains, and thus so do the scientists who study them.

It is physically difficult to get to and work in the rocky, cold, high elevations that make up the snow leopard habitat. Additionally, these scientists also work in some of the world's most contentious and politically contested border regions (as made evident by the close call between the aforementioned graduate student and the ITBP). Any map purporting to show the snow leopard's complete range includes national borders that are interrupted in places as simply 'Lines of Actual Control', as between China, India and Pakistan. In other range countries, the country borders date to the dissolution of the Soviet Union in 1991. Politically, there are many places where snow leopards are found, but scientists are not (or are seldom) allowed. Beyond these national borders are formal and informal internal borders within states defined by culture, ethnicity, linguistic region or religion (as with Kashmir, Tibet, Xinjiang or Ladakh, for example). The snow leopard brings to light the concept of 'border' both inside and outside the state, but also between different ways of perceiving and understanding the world. The snow leopard has enabled conservationists and scientists to overcome the many borders that exist among them - borders which they either would not be aware of, or would not be challenged to overcome were it not for their strong drive to understand and protect this beautiful (charismatic) animal.

In the context of this volume's collaborative project investigating the intersections between Chinese and Indian histories of science, and their relationship both with each other and with larger narratives about the twentieth and twenty-first centuries, we have chosen to focus upon the history of research into and conservation of the snow leopard. This moves our project past the national divide and complicates questions of national origins or styles or influences - snow leopard science is created across borders (yet is still limited by state boundaries and politics). Snow leopard science results from a number of different ways of knowing, including those of Western, Indian and Chinese scientists; international scientific organizations; national and international NGOs; Buddhist monks; and Himalayan villagers. While early snow leopard science was heavily influenced (and led) by US-based scientists and funded by a USbased NGO, by the 1990s first Indian, and then Chinese, scientists began to move to the fore. Their conservation practices (and science) were increasingly dependent upon work with local Himalayan peoples and a shared framework that they developed based on their transnational communication and exchange. More broadly, this conservation science of snow leopards is part of a larger trend within conservation biology that involves the reconceptualization of what constitutes 'state-of-the-art' conservation of endangered species and habitats throughout the world to include a landscape approach, incorporating local peoples and their needs. 


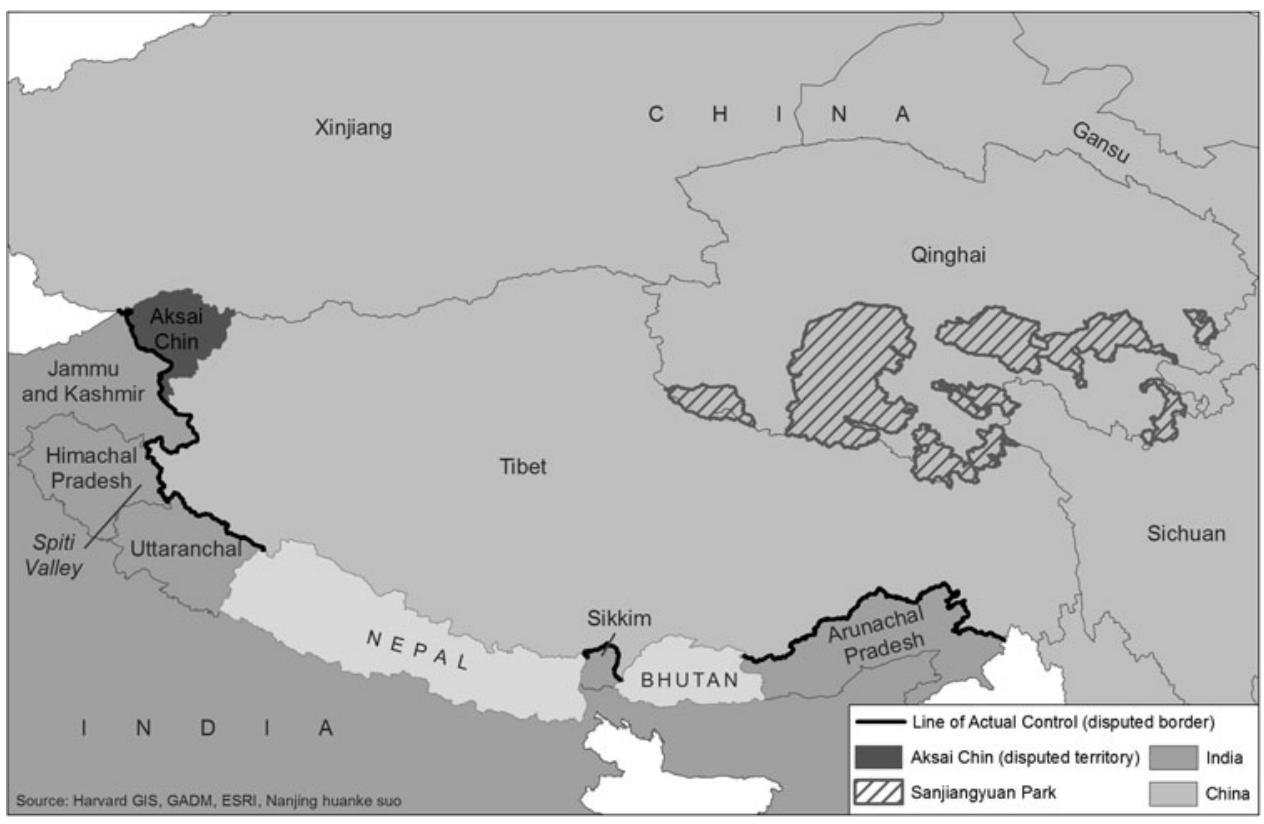

Figure 1. Map of snow leopard range across the Sino-Indian border. Map by Kathryn Hickey, 2016.

\section{Foundational science and surveys}

As long as people have lived (and herded livestock) in snow leopard habitat, they have certainly been aware of the existence of snow leopards. Awareness of this animal spread more slowly to the lowland seats of the civilizations that surrounded the Himalayas. Chinese observers have compiled extensive catalogues of regional flora and fauna for millennia. While it often is difficult to determine with certainty whether or not a citation in an ancient text refers to a specific modern animal, there are noteworthy commonalities between the ancient descriptions of a couple of animals, namely the $p i$ (貔) and the mengii (孟极), and the snow leopard. One classic text, the Er Ya 尔雅 from the era of the Qin dynasty (221-207 BCE) describes the term $p i$ 貔 as a large cat that is associated in turn with leopards and tigers, and sometimes as 'white leopard'. ${ }^{2}$ Some of China's snow leopard scholars concur that the term mengji 孟极, found in the Shanhai jing (Classic of Seas and Mountains), which is estimated to date back to the third century before the common era, is the world's earliest extant reference to the snow leopard. ${ }^{3}$

$2 \mathrm{Hu}$ Jinchu, Da xiongmao de yanjiu, Shanghai: Shanghai keji jiaoyu chuban she chuban faxing, 2001, 3, cited in E. Elena Songster, Panda Nation, Oxford: Oxford University Press, forthcoming, Chapter 1. Donald Harper, 'The cultural history of the Giant Panda (Ailuropoda melanoleuca) in early China', Early China (2013) 35, pp. 185-224, 219.

3 Zhou Shiqi, 'Shanhai jing mengji ji xuebao kao' (Examining mengji and xuebao in the Classic of Seas and Mountains), Zhongguo keji shi liao (China's History of Science and Technology) (1991) 12(2), pp. 84-87, cited 
While these do not constitute scientific observations per se, they reflect long-standing awareness of the presence and basic traits of snow leopards. Local terms for the animal do not seem to crystallize in the modern form until the twentieth century. The term xuebao (雪豹), which is a literal translation of 'snow leopard', appears in Chinese dictionaries in the early $1920 \mathrm{~s},{ }^{4}$ reflecting influence from Western terminology and taxonomical studies at the time.

In modern times, China took early action to list the snow leopard as a protected species. It actually appeared on China's protected-species list in 1962 (well before its Indian or US listing as endangered in 1973). In 1962, however, Chinese officials listed it only as a second-tier (not a top-tier) protected species (it would achieve top-tier rating in 1988). ${ }^{5}$ Although a number of regionally based surveys of local fauna had been conducted in the late 1950s and early $1960 \mathrm{~s},{ }^{6}$ the snow leopard's appearance on this national-level list of protected species in China was not the result of extensive scientific or species-specific surveys, but of a general sense that it was somewhat rare. While there is no extensive discussion in the document that articulates why each animal was designated to the list of a given level of protection, the top-tier protected species are described as 'precious, rare, and special', numbering nineteen in total. This list, with the giant panda achieving first billing, also contains other animals indigenous only within China's national borders like the golden-haired snubbed-nose monkey and Tibetan antelope, and such high-profile animals which had already achieved widespread recognition as the north-east tiger (or Siberian tiger) and black-necked crane. The list of second-tier protected species, thirty-eight in total, are animals 'of particular economic value, few in number, presently of a known limited number, or specific animals unique to China'. ${ }^{7}$ Although the snow leopard is traded in parts for its medicinal bones and soft, warm and beautiful coat, the challenge in spotting, let alone trapping, this animal dramatically lessens its appeal as game. A border animal, it is not unique to China. It thus likely landed on this list simply because of its apparent rarity.

Not long after these lists were created, China was swept into chaos by the Cultural Revolution (1966-1976). Certain types of scientific work did continue amid the volatile and anti-intellectual ethos of the era, but these were generally limited to such nationglorifying projects as expeditions up Chomolungma (Mt Everest) and giant panda surveys. ${ }^{8}$ Chasing elusive second-tier protected species that also existed in many other

in Juan Li, 'Ecology and conservation strategy of snow leopard (Panthera uncia) in Sanjiangyuan Area on the Tibetan Plateau', PhD dissertation, Peking University, 2012, p. 2; Ma Ming et al., Xinjiang xuebao (Snow Leopards in Xinjiang), Beijing: Science Press, 2013, p. 7.

4 Ma Ming et al., op. cit. (3), p. 565.

5 PRC Guowu yuan (State Council), 'Guowu yuan guanyu jiji baohu he heli liyong yesheng dongwu ziyuan de zhishi' (State Council notice concerning the active protection and rational use of wild-animal resources), Guolin Tanzi 287 hao, 14 September 1962, p. 3.

6 See Liao Yanfa and Tan Bangjie, 'A preliminary study on the geographical distribution of snow leopards in China', in Helen Freeman, India Dept of Environment, Forests, and Wildlife, International Snow Leopard Trust et al. (eds.), Proceedings of the Fifth International Snow Leopard Symposium, Delhi: International Snow Leopard Trust, 1988, pp. 62-63.

7 PRC Guowu yuan, op. cit. (5), p. 2.

8 Songster, op. cit. (2), Chapter 4. 
countries was not a priority in China at the time. The value of asserting China's claim over its borderland home range, however, did mean that the snow leopard was included among other integrated fauna surveys conducted during the Cultural Revolution, but none were specific to this large cat. ${ }^{9}$ In spite of awareness of the presence of this animal for thousands of years by both local peoples in its habitat and urban elites, scientific studies of the snow leopard did not really begin in China until the 1980s, and then occurred in part as a result of the prodding and participation of the renowned US biologist George B. Schaller. One must turn to India to find the earliest published scientific study of the snow leopard.

This first study on snow leopards that was more than just a recounting of their presence or absence in a landscape was written by the Indian mountaineer and schoolteacher Hari Dang. In 1967 he published 'The snow leopard and its prey' in Cheetal, the modestly subscribed journal of the Wildlife Preservation Society of India. ${ }^{10}$ Dang was part of a group of wildlife enthusiasts based at an elite preparatory school in Dehra Dun (the Doon School), in the foothills of the Himalayas. In 1964 they had begun the Himalayan Wildlife Research Project, which continued for more than forty years. In a retrospective article about his work in the Himalayas, written in 2003, Dang remembered the enthusiasm of those early years, even then tempered by a sense that they were observing an ecosystem in crisis. The year 1964 was less than two years after China's takeover of Aksai Chin in Ladakh, and only five years removed from the Chinese occupation of Tibet and the flight to India of the Dalai Lama and thousands of other Tibetan refugees. There was a palpable sense that Himalayan geopolitics was bad for wildlife:

The Tibetan occupation by China, and the subsequent [building of] roads all along the North of the Himalaya, with feeders to our borders, brought armed conflict and wayward soldiers to impoverished, hopeful mountain villagers ... to the excessive hunting pressure immediately after the war years and the fifties was added the road-building, para-military policing, and the troop concentrations and activity along the newly alive borders. ${ }^{11}$

Scientists working along the line of control between India and China in the 1990s (India has thus far refused to ratify the border as legitimate, still insisting that China return Aksai Chin) reported that the border region is still littered with bunkers, fortifications and even landmines from this period.

9 Ni Xinmin, 'Gansu sheng gan nanzang zu zizhi zhou zhengui dongwu ziyuan diaocha' (Survey of precious animals in the autonomous region of southern Tibet and in Gansu Province), Chinese Journal of Zoology (1979) 2(14), pp. 36-38; anon., 'Xinjiang weiwuer zizhi qu zhengui dongwu kaocha gongzuo 1975 nian du jiben jieshu' (Preliminary conclusions for the 1975 investigation work on the precious animal species in the Xinjiang Uyghur autonomous region), Forestry of Xinjiang (1975) 3, p. 25; Zhongguo kexue yuan Xizang kexue kaocha dui (Chinese Academy of Science Tibet scientific investigation team), 'Woguo xizang zhumuqima feng diqu ziran tezheng he dizhi fazhan shi' (A historical study of the distinctive features and geological development of the southern region of our nation's Tibet and the Zhumuqima mountainous region), Chinese Science Bulletin (1973) 1, pp. 11-21.

10 Hari Dang, 'The snow leopard and its prey', Cheetal: The Journal of the Wildlife Preservation Society of India, Dehra Dun (October 1967) 10, pp. 72-84.

11 Hari Dang, 'Notes on Himalayan wildlife', in Dang (ed.), Himalayan Environment: Issues and Concerns in Conservation and Development, Delhi: S.K. Gorg, 2003, 35-47, p. 37. 
Dang and his colleagues with the Himalayan Wildlife Research Project were amateur scientists - they collected a great deal of natural-history data, but were not full participants in the international scientific community. They were not completely isolated, however: they listed as technical advisers a mixture of Indian forestry officers, oldguard Indian conservationists such as E.P. Gee, and Indian and US biologists, chief among them the ubiquitous George Schaller. Schaller is now widely considered the most accomplished field biologist of the second half of the twentieth century. In 1963 Schaller had just published his well-received book on mountain gorillas, and was in India doing the research that led to his groundbreaking The Deer and the Tiger (1967), the first scientific study of tigers. While in India, Schaller met with dozens of scientists and foresters throughout the country. ${ }^{12}$ Dang and his colleagues in Dehra Dun were among the people Schaller met and advised. Schaller subsequently credited Dang's 1967 article as the first study of this species, although the regional publication was not available to most non-Indian scientists at that time.

Dang did not follow up the 1967 study with additional published work on snow leopards, but Schaller, after finishing his tiger research, decided that he wanted to work on Himalayan wildlife. Schaller's interest in working in the Himalayas came at a time when the Indian government was increasing restrictions on scientists - particularly US scientists - even as India began to invest heavily in conservation. Ironically, this was in part spurred by US support of Pakistan, China's ally, in the 1971 India-Pakistan War. President Nixon hoped to curry favor with China prior to his famous trip there the next year - one of India's responses was to restrict access to its fields and forests for US scientists. Research that involved work in the mountains along India's sensitive and contested borders with Pakistan and China was even less likely to be approved, though it had been somewhat restricted throughout the 1960s as well. As Dang recalled,

the difficulty of including foreign nationals in Indian expeditions into the hyper-sensitive border regions of the Himalaya discouraged foreign foundations, and the International Union for the Conservation of Nature/World Wildlife Fund was discouraged from helping the Himalayan Wildlife Research Project work because of the then Indian and Western differences in attitudes at the political level. ${ }^{13}$

In India, all snow leopard habitat was in sensitive border regions, and this meant that little snow leopard research was conducted in India in the 1970s and early 1980s. Instead, India's conservation focus during the 1970s was almost completely on tigers. Project Tiger was begun in 1973 to global acclaim, and it was in many regards a nationalist programme - initially only government foresters were allowed to conduct research on tigers.

Denied permission to work in India, Schaller instead went in 1969 to Pakistan's Himalayas. Schaller was studying wild sheep and goat species in the mountains, but while he was there he lucked into a week-long observation of a snow leopard and cub. He was hooked - both on the Himalayas and on snow leopards. Upon his return

12 Michael Lewis, Inventing Global Ecology: Tracking the Biodiversity Ideal in India, 1947-97, Athens: Ohio University Press, 2004, esp. Chapter 3.

13 Dang, op. cit. (11), p. 46. 
from the 1969-1970 fieldwork, Schaller wrote a popular article for National Geographic about the snow leopard. The photographs included with the article were the first published of a snow leopard in the wild, highlighting the animal's elusiveness and rarity. ${ }^{14}$

The visually striking snow leopard quickly became a symbol for Westerners of a particularly romantic version of the wild Himalayas and the mountain highlands of Central Asia - a land of trekkers, mountaineers, Tibetan lamas and dreams of Shangri-La. In 1972 George Schaller invited the well-regarded author Peter Mathiessen to accompany him on an expedition to north-west Nepal to the 'Crystal Monastery' where a Buddhist lama had ordered local residents to not harm the bharal (or Himalayan blue sheep). As Mathiessen later wrote,

there was bound to appear that rarest and most beautiful of the great cats, the snow leopard. [Schaller] knew of only two Westerners - he was one - who had laid eyes on the Himalayan snow leopard in the past twenty-five years; the hope of glimpsing this near-mythic beast in the snow mountains was reason enough for the whole journey. ${ }^{15}$

After several months in the field through 1973-1974, Mathiessen found only signs of snow leopards (Schaller saw a quick glimpse of one while trekking home). Unswayed, Mathiessen titled his 1978 account of his travels with Schaller Snow Leopard, and won the National Book Award for non-fiction that year. The book was as much a meditation on Buddhism, the mountains and the human search for meaning, spurred by an exotic landscape and exotic culture, as it was about the snow leopard - and indeed, he devoted considerably more time in the book to discussing Buddhism than science. The book served to cement Western interest in the snow leopard as a symbol, and helped create an association among Western readers between Buddhism and conservation of charismatic mammals in the high Himalayas. Suggestively, the text also indicates that in their months of wide-ranging discussions, Mathiessen, a practising Buddhist who saw the trip as a pilgrimage, had many opportunities to introduce Schaller to a wide variety of Buddhist saints and ideas. These included the lama Milarepa, whose pronouncements on animals would later be recorded on cards that Schaller handed out to villagers while working in Tibet, a practice that he engaged in at least since 1991, if not before. ${ }^{16}$

Through the rest of the 1970s, a few field biologists (working on other species) attempted to photograph or otherwise observe snow leopards in the midst of their work - usually unsuccessfully. In one of the earliest studies attempting to estimate population over part of the animal's range, Rodney Jackson, a young US-based South African, spent the winter of 1976-1977 searching for snow leopards in Nepal, near where Schaller had been. He found evidence of five, but never saw any. ${ }^{17}$ As the snow

14 George B. Schaller, 'Imperiled phantom of Asian peaks', National Geographic (1971) 140, pp. 702707,702 .

15 Peter Mathiessen, Snow Leopard, New York City: Viking Books, 1978, p. 3.

16 On the conservation cards see George Schaller, A Naturalist and Other Beasts: Tales from a Life in the Field, San Francisco: Sierra Club Books, 2007, p. 262.

17 Mathiessen, op. cit. (15), p. 330. 


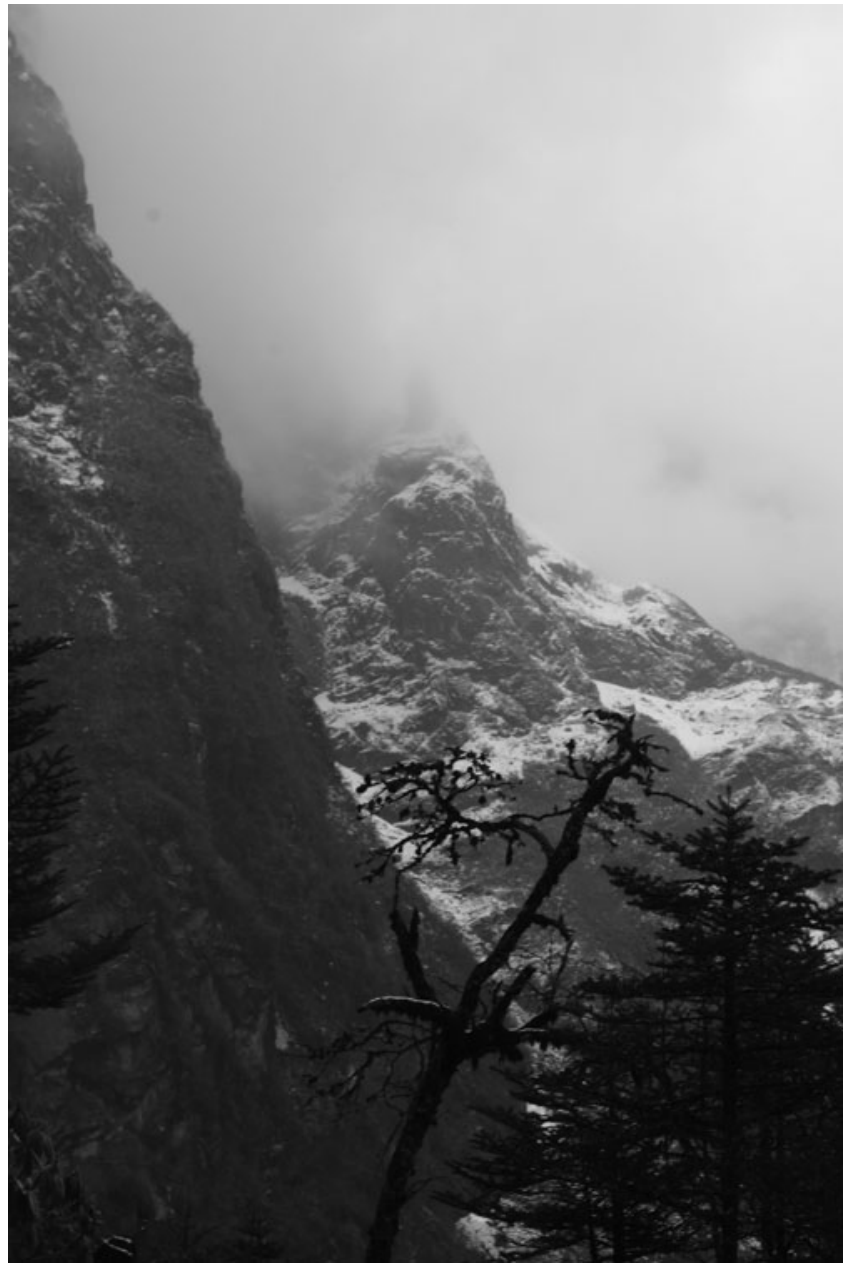

Figure 2. The rugged home range of the snow leopard in the Indian Himalayas. Photo by Michael Lewis.

leopard was so difficult to observe, conservationists made the logical assumption that it was scarce. Thus it had been included in the endangered species list of the USA and of India (both in 1973), and in the global CITES convention (1975), both more than a decade after China's initial tier-two listing of the species. In all of these cases, this was more of a precautionary ruling, as literally no one knew how many snow leopards existed (this continues - in 2015, scientists still were not confident of snow leopard populations in any of its home range countries.) Other than listing the species as endangered, and thus outlawing any trade in snow leopard furs or body parts, state-level conservation policies in the 1970 s were notable primarily by their absence. 


\section{Snow leopard science in the era of tigers and pandas}

Though there was some attention given to snow leopards throughout the 1970s in places such as Nepal, there are no recorded snow leopard-specific surveys from India or China during this time. They were, however, included in a few integrated animal surveys conducted in the snow leopard range in the provinces and autonomous regions of Xinjiang, Gansu and Tibet. ${ }^{18}$ Few resources were available for directed research, however, and little could be done with the data until after the Cultural Revolution was over. After 1978, though, Deng Xiaoping's efforts to internationalize China and advance China's science and technology (one of the Four Modernizations) broadened the options for scientific study and opened the door to foreign scholars and their expertise in a wide spectrum of fields. One of the initial scientific field projects that benefited from this shift in policy was China's first wild giant panda behavioral study. In 1979, the WWF (World Wildlife Fund, now World Wide Fund for Nature), which had a vested interest in supporting research on its panda mascot, contributed funding and helped to recruit (who else) the leading wildlife specialist George B. Schaller to run the study.

By 1980, then, both India's Project Tiger and China's giant panda conservation programmes were humming, to global popular acclaim. In retrospect the two projects were, scientifically, very different: the panda programme (with Schaller's assistance, and tied to international NGOs like the WWF) provided seed for the growth of Chinese conservation science. Project Tiger, maintained under the strict control of the Indian Forestry Service, became a preserve management programme with almost no scientific component, where scientists (Indian and otherwise) were actively prevented from studying tigers anywhere in India through the 1970s. Thus a generation of Chinese conservation biologists cut their scientific teeth on pandas, while none of the early Indian conservation biologists studied tigers. Across the globe a number of other species-specific conservation programmes were taking off - from condors in California to jaguars in Belize - and field biologists were organizing themselves into the new Society for Conservation Biology, founded in 1986, the same year E.O. Wilson popularized the term 'biodiversity'. ${ }^{19}$ Conservation biologists were increasingly savvy about the possibilities of using charismatic animals as flagship species - popular symbols for an ecosystem - or as umbrella species (if you save the wide-ranging apex predator, you save everything that lives in its habitat). ${ }^{20}$ It was in this context that scientific and conservation interest in snow leopards increased dramatically within China and India. ${ }^{21}$

As with pandas and tigers, snow leopard science developed in distinctly different paths in the two countries. In India the government took an active role in approving and overseeing snow leopard surveys and conservation schemes. In China, while government

18 Ni Xinmin, op. cit. (9); anon., op. cit. (9); Zhongguo kexue yuan Xizang kexue kaocha dui, op. cit. (9).

19 See Lewis, op. cit. (12).

201990 IUCN Red List of Threatened Animals, Cambridge: World Conservation Monitoring Centre, 1990; for context see Lewis, op. cit. (12).

21 Outside India and China, in 1981, the Snow Leopard Trust was founded, and the Rolex foundation gave Rodney Jackson a grant to do the first radio collaring of snow leopards in Nepal, as described in Darla Hillard, Vanishing Tracks: Four Years among the Snow Leopards of Nepal, New York: Arbor House Publishing Company, 1989. 
approval was, of course, needed for any research to be done, Schaller and his Chinese collaborators conducted their surveys without being part of a specific governmental programme. As he started wrapping up his panda project, Schaller began making plans for projects on fauna a bit higher up the mountain. Schaller and a group of Chinese colleagues conducted snow leopard and ungulate surveys from 1984 to 1987 (seven months inclusive from this range of years was spent in the field, in Qinghai and Gansu). Schaller, Liao Yanfa and Tan Bangjie knew that their surveys were incomplete; Liao and Tan wrote of Xinjiang that its snow leopard population must be high, given its habitat, but they had not surveyed that region. And in regard to the Tibet Autonomous Region (TAR), they wrote that 'most parts of these Tibetan mountains are still unexploited and uninvestigated ... Hence the status of the snow leopard is not clear in Tibet'. ${ }^{22}$ These regions were unexplored not for lack of interest, but because '[q]uite a large part of plateau and mountain district, especially the southwestern part of Qinghai, the southwestern and southeastern parts of Xinjiang, and the remote north-western parts of Tibet, are not yet opened to faunal investigation'. ${ }^{23}$ Collaborating with colleagues, including government foresters and academics from Xinjiang, Shaanxi, Sichuan and Beijing, Schaller conducted more surveys of the snow leopards and other animals in Xinjiang's Taxkorgan Reserve (on the border with Pakistan and Afghanistan) and in Qinghai and Gansu Provinces. ${ }^{24}$

China more generally and snow leopard areas more specifically were enjoying a resurgence of conservation policy activity throughout the 1980s. Although the national protected species list was not revised until the end of the decade, the snow leopard got a boost from second-tier protection status with the help of new regional policies. In 1983 the north-west provinces and autonomous regions of Shaanxi, Gansu, Xinjiang, Ningxia and Qinghai (all snow leopard provinces, and all surveyed in the mid-1980s) created a Five-Province (and Region) Wildlife Protection Committee to hold meetings and conduct research on wildlife protection management. ${ }^{25}$ With such heightened wildlife protection prioritization, the snow leopard achieved full legal protection in Qinghai that same year. ${ }^{26}$

These were fabulous developments for China and global conservation biology, but proved to be no match for the conservation challenges on the ground. While conducting research in these areas between 1984 and 1987, both Schaller and his Chinese colleagues gained an acute appreciation of the difficulties of doing conservation work in areas where human populations are engaged in sustenance living and cannot be removed. The economic loss of livestock to predation by snow leopards and other wild carnivores

22 Liao and Tan, op. cit. (6), p. 60.

23 Liao and Tan, op. cit. (6), p. 52.

24 George B. Schaller, Li Hong, Lu Hua, Ren Junrang, Qiu Mingjiang and Wang Haibin, 'Status of large mammals in the Taxkorgan Reserve, Xinjiang, China', Biological Conservation (1987) 42, pp. 53-71; George B. Schaller, Ren Junrang and Qiu Mingjiang, 'Status of snow leopard Panthera uncia in Qinghai and Gansu Provinces, China', Biological Conservation (1988) 45, pp. 179-194.

25 Li Yuming, 'Yesheng dongwu baohu guanli' (Wild animal protection management), in Zhongguo Linye Nianjian (China Forestry Yearbook), 1949-1986, Beijing: Zhongguo linye chuban she, 1992 (1987), p. 81.

26 Schaller et al., op. cit. (24), p. 192. 
could be devastating to herding families, yet during the mid-1980s the Chinese government did not have the funds to fully reimburse families for their losses. Shifts in herding techniques to better protect the livestock were impositions from the outside on traditional practices and usually required more work by more members of a household already stretched. Schaller and his colleagues concluded that 'protective steps must be accompanied by measures which improve the living standard of the people without further disrupting the environment'. ${ }^{27}$ A tall order certainly, but it was accompanied by some specific creative solutions, such as solar stoves (to reduce dependence on wood for fuel), greenhouses and fruit groves (to diversify resource dependence), handicraft sales and tourism (for added income). ${ }^{28}$ All of these suggestions required some capital and some follow-up by wildlife protection staff who very literally had a lot of ground to cover. The Taxkorgan Natural Reserve alone was 14,000 square kilometres. While these solutions were not implemented right away, they reflected a changing focus in conservation towards carefully considering the livelihoods and well-being of local villagers. In the near term, these surveys by Schaller and his Chinese colleagues served to bring the snow leopard into focus as a major species of concern within China, and it was formally listed as a top-tier nationally protected species in 1988, implemented in $1989 .{ }^{29}$

Another outcome of these surveys bore fruit more slowly. In thinking about the many challenges embedded in remote wildlife protection management, Schaller and his team returned to one of Schaller's insights from his 1973-1974 trip with Mathiessen to the Crystal Monastery in Nepal (near the border with Tibet). Schaller had chosen that location to study Himalayan species largely because of the existence of religious prohibitions against killing blue sheep surrounding the sacred site, and his hope that there would be greater prey densities. Now in China, Schaller returned to this, with the idea that the Buddhism of the local villagers could play a role in conservation. The Status of the Snow Leopard in China study concluded with the observation, 'Most pastoralists are Tibetans whose Buddhist religion predisposes them against killing wildlife. Using religious sentiment as a basis, an education programme might encourage some herdsmen to lay down arms and communes to establish their own reserves, especially around temples.' 30 Although there is little evidence that scientists engaged in any kind of direct collaboration with Buddhist monasteries in the 1980s (as opposed to the conversations and interactions that anyone passing through the regions surely would have), the concept and the degree to which it indicated that religious practice was flourishing in western China were remarkable in themselves. Less than a decade from the close of the Cultural Revolution, in many other parts of China people remained cautious in their practice of religion. Such an observation is as much a testament to the remoteness of this region as it is to shifts that were taking place in China's culture and ethos. These ideas of collaboration between scientists and Buddhist monasteries would be further

27 Schaller, Ren and Qiu, op. cit. (24), p. 70.

28 Schaller, Ren and Qiu, op. cit. (24), p. 70.

29 Chen Maoyun and Ma Xiangcong, Shengtai faxue (Ecological Law), Xi'an: Shaanxi renmin jiauyu chuban she, 2000, pp. 228-229.

30 Schaller, Ren and Qiu, op. cit. (24), p. 193. 


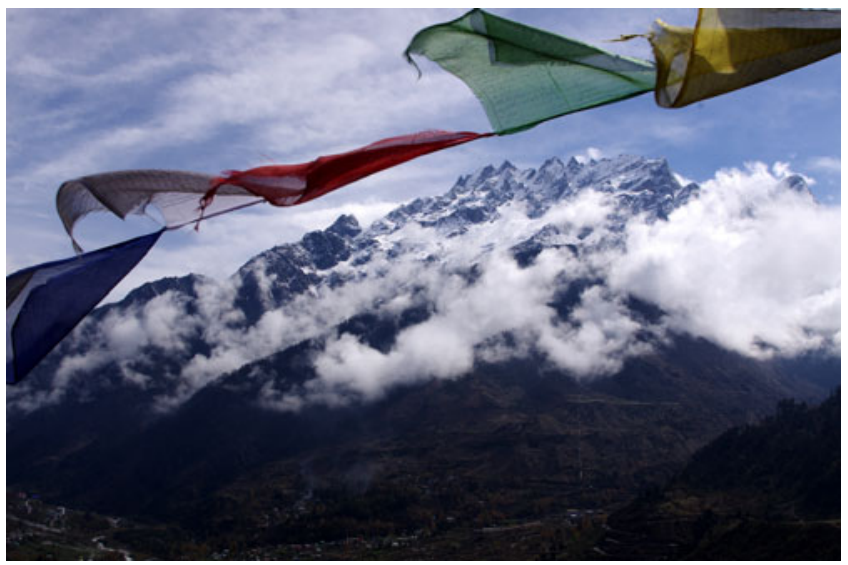

Figure 3. Buddhist prayer flags in the Himalayan home range of the snow leopard. Photo by Michael Lewis.

developed and acted upon in the work of Lü Zhi, Li Juan and other snow leopard researchers nearly twenty years later.

At the same time as Chinese scientists and Schaller conducted snow leopard surveys in China and began to consider a model of conservation grounded in the notion that they should be integrated with local religious beliefs and livelihoods, within India the government began to relax restrictions on collaborations with Western (especially US) scientists. Two scientists working in India, David Mallon (working on the ecology of Ladakh, from the University of Manchester) and Michael Green (working on a PhD on musk deer, from Cambridge) wrote short articles about the presence of snow leopards in their study areas in the early 1980 s. ${ }^{31}$ Both of these studies were incidental, however, and snow leopards were not the true focus of either scientist, nor did they aspire to comprehensiveness, nor did they reflect a large-scale collaboration. That would come instead from an official decision by the Indian government.

In a 1983 review of India's progress in protecting endangered species, the Department of Environment noted that for many endangered species, even rudimentary life history or population data was not known. They thus recommended that the government seek outside expertise in coming up with suitable management plans for key endangered species. ${ }^{32}$ This formally opened up a resumption of large-scale collaboration between Western and Indian scientists. With regard to the snow leopard, this led to the government agreeing to allow a newly created government institution, the Wildlife Institute of India (WII), to collaborate with the US Fish and Wildlife Service (USFWS) and the (International) Snow Leopard Trust (SLT - based in Seattle, this NGO was founded

31 M.J.B. Green, 'Status, distribution, and conservation of the snow leopard in north India', International Pedigree Book of Snow Leopards (1982) 3, pp. 6-10; D. Mallon, 'The snow leopard in Ladakh', International Pedigree Book of Snow Leopards (1984) 4, pp. 23-37.

32 Department of the Environment, National Wildife Action Plan, New Delhi: Government of India, 1983. 
by zoo worker Helen Freeman in 1981). The resulting Indo-US Snow Leopard Project assessed the status of snow leopards in north-western India, and made conservation policy recommendations. US scientist Joseph Fox and the director of WII, H.S. Panwar, a former director of Project Tiger, were the primary collaborators, but as Panwar was an administrator more than a scientist, a team of young Indian field researchers were recruited to work with Fox in the field in 1985-1986. The state government of Jammu and Kashmir, particularly, embraced the newfound national governmental interest in snow leopards. There were no tiger reserves in Jammu and Kashmir. The state department of wildlife saw this as a conservation initiative more suited for their alpine landscape, and thus a way to join the burgeoning conservation state apparatus within India.

The culminating event of the Indo-US Snow Leopard Project was the 5th International Snow Leopard Symposium, hosted by the state of Jammu and Kashmir in its capital city of Srinagar, and co-sponsored by the Snow Leopard Trust and the government of India. Since 1982 the SLT had organized annual symposiums on the snow leopard - those had been held in Helsinki, Zurich, Seattle and Krefeld, West Germany (all associated with zoos). In 1986, for the first time, the SLT was able to hold the symposium in a country with native populations of snow leopard and the emphasis was on high altitude habitat and conservation of the species in the wild' rather than in zoos. The papers presented at this symposium (and subsequently published) included work on India, China (by Schaller's collaborators Liao Yanfa and Tan Bangjie), Nepal (Rodney Jackson), Mongolia and the Soviet Union. The science shared at this meeting was primarily surveys, as noting the presence or absence of snow leopards, and developing techniques for estimating populations, were the state of the art. ${ }^{33}$ At the conclusion of the symposium, the government of India announced, to great fanfare, 'the initiation of a new research and management program for the snow leopard and its high altitude ecosystem'. ${ }^{34}$ This was to be the first snow leopard conservation scheme in the world. It seemed to the attendees that a turning point in snow leopard conservation and science had been reached - scientists doing work in the field were brought together to share their findings in a country that was willing to use those findings to pursue new conservation policies.

Following the conference, the government of India and the Ministry of Environment and Forests published a Snow Leopard Conservation Scheme in 1988. Written by M.K. Ranjitsinh, a member of the Indian Administrative Service and one of the founders of Project Tiger, the Snow Leopard Conservation Scheme was closely based on the topdown tiger model - the snow leopard would be saved via a series of protected areas

33 In an extensive survey of the published scientific literature on snow leopards, as of 2015 research was still often geared towards the most basic of questions: are there snow leopards in a given area, and if so, how many? Some versions of this survey literature focus on different techniques for surveying snow leopards, including versions of direct observation, camera traps, scat and sign collection, DNA analysis of scat and hair to identify individuals, habitat analysis via satellite data and GIS, and attempts to use prey numbers and densities to determine possible predator densities.

34 Helen Freeman, 'Introduction', in Freeman et al., op. cit. (6), pp. ix-x. 
scattered through the Himalayan landscape. ${ }^{35}$ This plan never made it off paper. It proposed the conservation of a charismatic animal, but it had a narrow range of support within the Indian government, and it lacked any associated nationalist elements, the involvement of many scientists or foresters, or support from other Himalayans states outside Jammu and Kashmir. Within months of the scheme's release, completely unrelated, Kashmir's separatist movement moved to a radical (and more militarized) stage; when that state devolved into near war the Snow Leopard Conservation Scheme died.

\section{Scientists, naturalists and place}

Snow leopard science in the 1980s was characterized by a dramatic increase in international attention to snow leopards, the spread of US-based scientific expertise through Schaller and Fox, the creation of a crucial US-based NGO (the SLT), and the attempt to spread some of that expertise (and funding) to Chinese and Indian collaborators while conducting initial snow leopard surveys in both countries. Though the next decade did not include any notable governmental actions (such as China's 1988 change in the protected status of snow leopards, or India's abortive attempt at a snow leopard conservation scheme in 1988), the 1990s were a period of steady growth in the development of both Chinese and Indian scientific expertise within conservation biology. The key development in this decade was the gradual transition towards more scientific approaches to the study of snow leopards among young scientists. This shift and growth of expertise through the 1990s made possible an explosion of scientific and conservation work on snow leopards in the early twenty-first century. A search of a Chinese academic journal database revealed that during the 1980s there were approximately ten articles on the snow leopard, six of which were scientific articles. During the 1990s, this increased threefold. In the fifteen years since 2000, however, 287 articles related to snow leopards were written. ${ }^{36}$ Within China, even as increasingly substantial snow leopard research projects were launched, they usually depended heavily on private and often external funding - which, under Deng Xiaoping's market reforms, were much easier to access. In contrast, the India/US/SLT Indo-US Snow Leopard Project of the mid-1980s continued to provide the context for Indian developments.

While the Indo-US Snow Leopard Project was a conservation policy dead end, it was successful in nurturing and supporting young Indian scientists. When the co-directors of the project, Panwar and Fox, hired the field assistants to help with the surveys, one of the successful applicants was a young man fresh from his master's degree in botany, Raghu Chundawat. He had never before been in the Himalayas, and (in his own words) had gone to the university largely to play cricket. Chundawat's life was transformed by his first field experience in the high Himalayas, and his experiences tracking snow leopards.

35 Ministry of Environment and Forests, Snow Leopard Conservation Scheme, New Delhi: Government of India, 1988.

36 Li Juan, personal correspondence, search conducted in CNKI database, 2 October 2015. A similar study conducted in India shows the same trend, as described in the National Snow Leopard and Ecosystem Protection Plan (2013). 
As a result of this fieldwork, and with the encouragement of Fox and Panwar, Chundawat decided to do a PhD on snow leopards and their prey.

Due to working in what was deemed a politically sensitive area, Chundawat had to turn down full fellowships at Washington State University and Colorado State. If enrolled in a US university, the government of India would have denied him permits to conduct his research. He thus enrolled at Jaipur University (in the desert state of Rajasthan). Although he did not have a formal US collaborator or adviser, Chundawat stayed in touch with Joe Fox and Dave Ferguson (the head of USFWS efforts in South Asia) throughout his project. In Indian universities, as in most in Europe, PhD students moved straight to fieldwork, with minimal classroom preparation. Spending ten months per year in the field, with his formal training in botany, not zoology or ecology, Chundawat relied heavily on the support of his unofficial US advisers. Working in Kashmir, despite the separatist movement (and in spite of losing months of field notes when the forest rest house he stayed in was burned down by rioters in 1989 or 1990), with minimal preparation in formal ecology, by 1992 Chundawat had produced the world's first PhD dissertation on snow leopards. His dissertation also happened to be the first document the Hindi-speaking Chundawat had written in English. ${ }^{37}$ The next year (1993) Chundawat was hired as a faculty member by WII, where he continued to study snow leopards, as well as beginning to work on tigers.

The Wildlife Institute of India, a new government institution with support from the UN's FAO and the USFWS, began training students in a master's programme that expanded to supporting $\mathrm{PhD}$ students by the 1990s. It was responsible for developing an astounding collection of scientists in its initial years. Its graduates have transformed conservation science in India, working in a wide range of governmental, university and private organizations. With regard to snow leopards, three scientists associated with WII stand pre-eminent: Raghu Chundawat, Yash Veer Bhatnagar and Charudutt Mishra. Even as Chundawat was completing his $\mathrm{PhD}$, Yash Veer Bhatnagar, who had come to WII to do a master's degree, stayed for a PhD studying Himalayan ibex. His project was funded by the USFWS (again, through Dave Ferguson) in collaboration with the Smithsonian Institution. Although his $\mathrm{PhD}$ was focused on ibex (awarded in 1997 by Saurashtra University, in collaboration with WII), Bhatnagar also wrote about snow leopards, and the high-altitude ecosystem more generally. His focus upon interactions between predators, prey, vegetation and ecology bespoke a more complex ecological science than earlier surveys.

This same shift in focus was also true of Charudutt Mishra, an Indian biologist who, after receiving his master's from the Wildlife Institute of India, received his $\mathrm{PhD}$ in highaltitude ecology from Wageningen University in the Netherlands in 2001. Mishra's research did not focus primarily upon snow leopards, but rather on the complex mixture of human and natural interactions in the high valleys of the Himalayas. Mishra was the first snow leopard scientist to have been formally trained both in

37 Raghu Chundawat, 'Ecological studies on the snow leopard and its prey species in Hemis National Park, Ladakh', PhD dissertation, University of Rajasthan, Jaipur, 1992. Interview with Raghu Chundawat, Delhi, 10 May 2013, transcript on file with Michael Lewis. 
India and abroad - and even further, his adviser had studied Africa, and was able to give Mishra a wider ecological perspective for his research. Both Bhatnagar and Mishra were recognized for their work internationally. Upon completion of his $\mathrm{PhD}$, Bhatnagar was invited by the SLT to begin the first 'country office' for the SLT in India. He continued in that position until he accepted a job at WII, at which time the position of India programme director was given to the newly graduated Mishra.

Within China, a new generation of conservation biologists was also moving to the fore. After a brief interregnum Schaller returned to China in the 1990s, where he followed up the earlier surveys with subsequent work with a new group of Chinese colleagues working on the Tibetan plateau. One of the young scientists who accompanied Schaller was Lü Zhi, who conducted research on chiru (Tibetan antelope) and other plateau fauna. Lü Zhi's dissertation adviser, Pan Wenshi, had himself worked with Schaller, and was one of the primary scientists and co-authors of Schaller's seminal wild giant panda behavioral study during the early 1980s, The Giant Pandas of Wolong. Lü Zhi thus represented a second generation of Chinese conservation biologists to work with Schaller - but now focusing on the Tibetan plateau rather than pandas. During the 1990s, Lü Zhi, Wang Dajun and Wang Hao, among others, contributed to what could be called the Peking University school of conservation biology and became an important bridge in the continuation of conservation studies in China with their work on the Tibetan plateau. Many of these scientists were simultaneously continuing giant panda research of their own and participated in multiple international research projects, as well as, in Lü Zhi's case, spending time at both Harvard and Yale.

In both India and China, as well as internationally, an increasing number of scientists developed expertise in snow leopard science and high-altitude ecology in the 1990s (not all of these scientists are mentioned in this paper). While many of these newer scientists were attracted to the beauty of the landscapes and the charismatic power of the snow leopard itself, they were trained differently than an earlier generation of naturalist-scientists, and had a different orientation to their fieldwork.

Schaller stands as the exemplar of the naturalist - the scientist who aspires to 'see the world whole'. In a 2010 interview, Schaller explained his approach to science:

People are so enamored of technology and DNA that universities spend less and less time teaching natural history ... And that's the basis of knowledge. You're losing generations of people who don't know much about the outdoors. And unless you go out and study what's in the field, you can't plan for conservation that well. You can measure how fast forest is being destroyed, you can measure the biomass of grassland, but you don't know any details. ${ }^{38}$

Throughout his life, Schaller avoided specialization on one species, let alone one ecosystem. By his 70s, Schaller had conducted path-breaking field studies on four continents. This did not mean that his work was that of a dilettante, however.

After completing his $\mathrm{PhD}$, Bhatnagar sent Schaller a letter. In it he explained that after five years of intensive monitoring and radio tracking of ibex, he basically confirmed what

38 As quoted in John Allen, 'A voice in the wilderness', On Wisconsin: University of Wisconsin Alumni Magazine (Summer 2010), pp. 22-29, 28. 
Schaller had already written after much less time in the field, more than a decade earlier. As Bhatnagar related the story,

So [Schaller] got back immediately, and I still have that letter ... And he clearly said, 'Look Yash Veer, don't be disappointed. I stopped with only observation. I made a story. You say the same things based on intensive sampling and that makes it more robust. And what you have seen in four or five years, it is valid ... You should be happy.' So it is a small thing, but as a Ph.D. student, coming from a person like George Schaller, it is a huge thing. ${ }^{39}$

Scientists who worked with Schaller in China echoed this fascination with his ability simply to know stuff. Li Juan, a student of Lü Zhi who in 2012 became the first Chinese scientist to write a $\mathrm{PhD}$ dissertation on wild snow leopards, was in the third generation of Chinese biologists to have worked with Schaller in the field. She distinguished her approach to science from Schaller's by saying, 'He [Schaller] is a naturalist; I am a field biologist.' As she continued it was clear that she admired Schaller's expansive understanding as well as knowledge of the multifaceted ways that each part of an ecosystem is interlinked. In contrast, she described her own approach as being extremely focused on a narrow aspect of study and conducting systematic measurements to test the scientific rigour of her inquiry. Working with Schaller, however, she gained a great appreciation for looking at nature with a broader perspective. She noted, 'Working with him enabled me to lay a strong foundation on which to build a better sense of the full picture of the ecosystem. This broader perspective has enabled me to ask much more important questions about snow leopards during my research. 40

Even as these younger scientists embraced a more formal and narrow focus for their science, they shared with Schaller the romance of field study in an under-studied region. In conversation, Bhatnagar admitted that he was not initially interested in snow leopards - he was more of a dog person, he said. He was, however, fully entranced by the landscape of the Himalayas. And he had read George Schaller, both the popular Stones of Silence and the more scientific Mountain Monarchs:

Mountain Monarchs of course gave a much clearer idea about the scientific angle, but in my case the romance of working in a place that you like, with something that you like, was more important than what you work on ... My take-home message from Stones of Silence was the romance of exploration, and realizing that much of this area is still to be explored. ${ }^{41}$

Not only Westerners were attracted to the romance of the high Himalayas.

\section{Traversing borders with the SLT}

With few exceptions, the Snow Leopard Trust (SLT) provided the initial institutional support, funding and even jobs to most scientists who have worked on snow leopards. Rodney Jackson - who began working in Nepal in the 1970s - spent a period in the

39 Bhatnagar interview, op. cit. (1).

40 Li Juan, interview, Beijing, 21 June 2013.

41 Bhatnagar interview, op. cit. (1); George Schaller, Mountain Monarchs: Wild Sheep and Goats of the Himalayas, Chicago: The University of Chicago Press, 1977; and Schaller, Stones of Silence: Journeys in the Himalayas, New York City: Viking Press, 1980. 
1990 s as the science and conservation director of the SLT, and it was he who began the country programmes, beginning with his hiring of Bhatnagar in India. When Jackson branched off to form his own NGO (the Snow Leopard Conservancy), Tom McCarthy (recruited by Schaller to work on snow leopards in Mongolia) took over as science and conservation director of SLT. When Bhatnagar left SLT for a period to work at the Wildlife Institute of India, McCarthy hired Mishra to direct the India programme. (This formally established a partnership with the Indian NGO the Nature Conservation Foundation, which Mishra had co-founded, and which became SLT's partner organization in India.) In 2008, McCarthy moved to a new NGO, Panthera. ${ }^{42}$ At that point, the SLT executive director Brad Rutherford invited Mishra to be the new science and conservation director of SLT - the first non-American to hold this position. This left Bhatnagar as the head of the SLT India office from 2008 until 2015 (he, along with Chundawat, had left the Wildlife Institute of India), after which Mishra's former PhD student, Kulbhunshansingh Suryawanshi, became the new India programme director. And since 2008, Lü Zhi has been the SLT coordinator for China. The SLT, though based in Seattle, has not just supported people from snow leopard range countries in the field, but also has moved them into positions of real leadership within the organization.

It is difficult to overstate the importance of the SLT providing an institutional home and support for scientists who had been working largely outside government positions, and in countries where snow leopard conservation did not 'move the needle' nearly as much as more nationalized animals (such as tigers or pandas). As the SLT began to support country offices (following India, they expanded into Kyrgyzstan, Mongolia, Pakistan and, in 2004, China) the NGO also became involved in supporting a number of experiments at the local level proposed by their various scientists. These ranged from livestock insurance programmes to vaccination programmes for livestock, building corrals to protect livestock from predation, snow leopard enterprises (where village women make handicrafts that SLT markets and sells, bringing the proceeds back to the local communities - totalling more than one million dollars thus far) and grazingfree zones. Where these experiments succeeded, they were institutionalized, and then attempted in other countries or other villages. This kind of support led to, for instance, Mishra being given the prestigious UK-based Whitley Gold Award in 2005, for his work with grazing sanctuaries and livestock insurance near the village of Kibber.

Beyond providing institutional positions and support, the SLT has also provided annual conferences, with attendant connections and networks. In 2000, the SLT decided to host a special Snow Leopard Survival Summit in Seattle, with the support of the USFWS. Designed to be a grand gathering of scientists from every range country, and an attempt to take stock of the global status of snow leopards and the relevant science, the summit was originally scheduled for the autumn of 2001, but 9/11

42 Founded in 2006, Panthera is a well-funded NGO that focuses more broadly on all wild cats. With a headquarters in New York City, Panthera has attracted leading talent, particularly from US scientists, including its current vice president, George Schaller, as well as McCarthy, who is the executive director of their snow leopard programme. 
necessitated a shift to the spring of 2002. The attendees for this summit were a who's who of snow leopard conservation, with representatives from every country with a population of snow leopards, and every important scientist either in attendance or (as with Schaller) commenting and advising from afar. At this summit, there were two primary emphases: establishing a snow leopard network for the rapid sharing of information, and working with range-country governments to establish a legal framework for snow leopard protection.

The Snow Leopard Network was an immediate solution to the first goal. It is a repository of scientific articles and technical reports concerning snow leopards, was the creator of the Snow Leopard Survival Strategy, and has proven to be a valuable resource for sharing information across national borders. It also runs a grants programme, which as of 2015 had supported more than fifty projects in various range countries. The Snow Leopard Network has an executive director - Tom McCarthy until 2010, and then Charu Mishra to present - as well as an elected steering committee, whose current chairperson is Lü Zhi.

The second goal of the Snow Leopard Survival Summit - establishing legal frameworks for protection in the range countries - was more diffuse in focus. In some cases, as with China, this meant first moving to establish a country programme. In other cases, as with India, it meant turning the attention of the country programme in place not just to focus upon disparate local efforts, but instead to create a systemic legal framework to protect snow leopards.

In India, this bore fruit when the government of India officially approved a new Project Snow Leopard in 2008. Planning for this had begun prior to the Snow Leopard Survival Summit, in a 2001 workshop in New Delhi. In a paper from that workshop, Bhatnagar (and colleagues including Tom McCarthy) reported that a justification for a new and expanded landscape-level conservation scheme for snow leopards had been made and largely accepted by attendees. ${ }^{43}$ This workshop was followed by years of intense effort by Mishra and Bhatnagar. After meeting with foresters from each of the five snow leopard range states in India, there was a national workshop in Ladakh to set goals for snow leopard conservation. From this, Bhatnagar and Mishra were assigned by the government of India to serve on the Project Snow Leopard drafting committee (along with representatives from all five states, representatives from conservation organizations like WWF, and scientists from the Wildlife Institute of India).

The document that this committee produced, and the government accepted, was radical within the context of state-sponsored conservation schemes. Other than its 'project' name, it bore almost no relation to Project Tiger. Rather than being a conservation scheme predicated on the exclusion of human uses from sacrosanct nature reserves, Project Snow Leopard was a landscape-level conservation plan. The central insight of this document is that conservation cannot occur only in protected areas

43 Y.V. Bhatnagar, V.B. Mathur and T. McCarthy, 'A regional perspective for snow leopard conservation in the Indian trans-Himalaya', National Workshop on Regional Planning for Wildlife Protected Areas, 6-8 August 2001, India Habitat Centre, New Delhi, GEF-India Ecodevelopment Project Initiative, Dehradun: Wildlife Institute of India, 2001. 
within the high Himalayas - park boundaries were yet another set of borders that snow leopards regularly traversed. Snow leopards were found throughout a vast range of nearly 100,000 square kilometers in India, a range which also included numerous human communities surviving on minimally available seasonal resources. Subsequently, satellite radio-collar studies of snow leopard home ranges have confirmed the essentiality of conservation at the landscape level - one radio-collared snow leopard in Pakistan covered an area of over 1,500 square kilometres, although Mongolian studies suggested an average home range of 365 square kilometres. ${ }^{44}$ Snow leopards require such a large home range that a nature reserve preserving a breeding population would have to be massive, and local peoples rely upon grazing domestic stock in those same wide expanses - they cannot be simply excluded, without grave consequences. The ecosystem, in biological terms, is unproductive for both snow leopards and people, and they both need relatively more space.

Thus, to save snow leopards, the key is not a 'business-as-usual' national-park model, but rather to convince park administrators (and thus the government) to work with human communities and science/conservation NGOs to manage landscapes that have a wide array of habitats and uses, and meet the needs of wildlife and people both. This requires saving not just snow leopards, but Himalayan human societies as well, by helping them achieve livelihood security without degrading their environment. In this, the project document prepared by the PSL Drafting Committee reflected many of the same insights and concerns as Schaller and his Chinese colleagues expressed in their surveys from the 1980s. This model, through Project Snow Leopard, became governmental policy in India as of January $2009 .{ }^{45}$ Beyond India, this new Project Snow Leopard was the state of the art within conservation biology. This approach shows an increasing focus upon protecting endangered species in large landscapes that include human communities and uses, as opposed to only sacrosanct national parks or protected areas (called 'fortress conservation'). ${ }^{46}$

Within China itself, following the Snow Leopard Survival Summit in 2002, three distinctly different groups began working on snow leopards. Earliest of these was the Chinese ornithologist Ma Ming, who began by first applying to the SLT to fund a small-scale project. His work transformed into a ten-year team project that also benefited

44 Yash Veer Bhatnagar and Charudutt Mishra, 'Conservation without fences: Project Snow Leopard', in Mahesh Rangarajan, M.D. Madhusudan and Ghazala Shahabuddin (eds.), Nature without Borders, Hyderabad: Orient BlackSwan, 2014, pp. 157-177, 160.

45 Bhatnagar interview, op. cit. (1). Also Ministry of Environment and Forests, Project Snow Leopard, New Delhi: Government of India, 2008.

46 For an India-specific review of the limitations of protected area-based conservation see Rangarajan, Madhusudan and Shahabuddin, op. cit. (44). For a more global review of the impacts of fortress conservation see Chris Conte, 'Wild places or domesticated spaces: applying the wilderness concept to Africa, Asia, and South America', in Michael Lewis (ed.), American Wilderness, New York: Oxford University Press, 2007, pp. 223-242; for an early expression of landscape conservation outside snow leopards see B.H. Green, E.A. Simmons and I. Woltjer, 'Landscape conservation: some steps towards developing a new conservation dimension', University of London, Department of Agriculture, Horticulture and Environment, 1996; for an example of how this approach is changing even tiger conservation see Pranav Chanchani, Barry R. Noon, Larissa L. Bailey and Rekha Warrier, 'Conserving tigers in working landscapes', Conservation Biology (2015), published online. 
from funding from the Xinjiang Conservation Fund. WWF-China was also involved in cooperative snow leopard projects early on. Ma Ming headed the Xinjiang snow leopard survey team, which began its work in 2004, the same year that SLT formally began its China programme. ${ }^{47}$ Tom McCarthy, who had been conducting research in Mongolia for years, and was serving as the science and conservation director of SLT at that time, worked with Ma to teach him about snow leopards. It appears that the bulk of Ma's work in Xinjiang was oriented towards surveys, as indicated by two articles that he published in 2005 and 2011.48 The results of the research that he and his colleagues conducted are collected into China's first book-length compendium of work on snow leopards, Xinjiang xuebao (Snow Leopards in Xinjiang), published in 2013 (this book is only available in Chinese, and is thus not yet part of international scientific discussions).

In 2007, independent of the SLT projects in India, Ma Ming's surveys, or the previous work by the scientists at Peking University, China's State Forestry Agency began supporting Shi Kun and his students in conducting snow leopard research in Xinjiang, Gansu, Sichuan and Tibet (he is at present head of the Wildlife Institute and associate professor at the College of Nature Conservation, Beijing Forestry University). Having earned his $\mathrm{PhD}$ in environment and resource management, Shi Kun's research interests have broadened from grassland ecology to snow leopard research. Although he has received some support from the SLT and serves on the steering committee for the Snow Leopard Network, Shi Kun's international collaboration originally focused on work with scholars, graduate students and post-docs from Oxford University's WildCRU (Wildlife Conservation Research Unit), where Shi Kun was a visitor. Though WildCRU in 2015 does not seem to have a current presence in snow leopard research, Shi Kun continues to work with Oxford University scholars, including zoologist Philip Riordan and graduate student Justine Alexander. Their published articles indicate that Shi Kun and the other SLT-supported scholars within China have been working on separate but parallel projects, at least through 2015.49

The third trajectory of snow leopard science within China began in 2008, which turned out to be a watershed moment in transnational cooperation between Chinese and Indian snow leopard scientists. Three things occurred in 2008-2009 - one, already discussed above, was the formal start of India's Project Snow Leopard, and Charudutt Mishra's ascension to the position of science and conservation director for SLT. A second, more suggestive than definitive in its impact, was that western China

47 Ma Ming et al., op. cit. (3), pp. ii, 567.

48 Ma Ming, B. Munkhtsog, F. Xu, T. Mardan, S.J. Yin and S.D. Wei, 'Markings as indicator of snow leopard in field survey, in Xinjiang', Chinese Journal of Zoology (2005) 40(4), pp. 34-39; Ma Ming, F. Xu, B. Munkhtsog, Y.Q. Wu, T. McCarthy and K. McCarthy, 'Monitoring of population density of snow leopard in Xinjiang', Journal of Ecology and Rural Environment (2011) 27, pp. 79-83 (in Chinese).

49 Philip Riordan, Samuel A. Cushman, David Mallon, Kun Shi and Joelene Hughes, 'Predicting global population connectivity and targeting conservation action for snow leopard across its range', Ecography (2015), published online; Justine Alexander, Penju Chen, Peter Damerell, Wang Youkui, Joelene Hughes, Kun Shi and Philip Riordan, 'Human-wildlife conflict involving large carnivores in Qilianshan, China and the minimal paw print of snow leopards', Biological Conservation (2015) 187, pp. 1-9. Information about WildCRU is available on their website, www.wildcru.org. 
became politically more difficult to work in. In the wake of the widespread Tibetan protests in 2008 in the Tibet Autonomous Region as well as the surrounding Sino-Tibetan areas, the Chinese government responded with increased presence and control over activities in these areas. ${ }^{50}$ Simultaneous to the government crackdown in TAR, a protest broke out in Xinjiang, followed by other incidents through August. Both of these political hotspots overlap with important snow leopard habitat and it became difficult to work and conduct research in both regions. The 2008 governmental response came with an explicit emphasis on 'scientific development' and an implicit devaluation of religious and other cultural expressions. ${ }^{51}$ This government-led heavy promotion of science thus imposed an ironic challenge, as the most cutting-edge approaches in emerging snow leopard conservation science involved the incorporation of Tibetan Buddhist teachings and outreach, just what the government sought to avoid. The third, and more immediate occurrence, was the introduction of SLT, through Mishra, to Peking University professor Lü Zhi and her environmental NGO, Shan Shui, at the Society for Conservation Biology conference in Beijing in 2009.52

Shortly after the tenth international snow leopard conference (hosted in Beijing by the Chinese Institute of Zoology), the SLT collaboration with Ma Ming in Xinjiang was coming to a close. As Mishra was made the SLT science and conservation director, he was tasked with strengthening the SLT country programmes, particularly in China. A few months later, at the 2009 Society for Conservation Biology annual meeting, Schaller introduced Mishra to a Chinese colleague whom he knew from her work on giant pandas and who had done fieldwork with him on the Tibetan plateau - Lü Zhi. Schaller suggested that Lü Zhi and the NGO Shan Shui (which she created and ran) would be the perfect collaborators for SLT in China. Mishra agreed, and he has been travelling to China each year since, working with Lü Zhi as she and her graduate students do work on snow leopards in Qinghai. Mishra has co-supervised Lü Zhi's graduate students, and it is apparent that he admires her students greatly: 'It's just so amazing to be able to find people like that who in many ways think like you and really want to approach conservation from the grass roots with a lot of regard for community. ${ }^{53}$ It is no accident that Charudutt Mishra and Lü Zhi work well together - both have clearly stated that they understand that conservation must occur in a matrix of human

50 Charlene E. Makley, 'The amoral Other', in Emily T. Yeh and Chris Coggins (eds.), Mapping Shangrila, Seattle: University of Washington Press, 2014, pp. 229-254, 251; Juan Li, George B. Schaller, Thomas M. McCarthy, Dajun Wang, Zhala Jiagong, Ping Cai, Lamao Basang and Zhi Lu, 'A communal sign post of snow leopards (Panthera uncia) and other species on the Tibetan Plateau, China', International Journal of Biodiversity (2013), published online; Juan li, Dajun Wang, Hang Yin Duojie Zhaxi, Zhala Jiagong, George B. Schaller, Charudutt Mishra, Thomas M. McCarthy, Hao Wang, Lan Wu, Ling Yun Xiao, Lamao Basang, Yuguang Zhang, Yuyun Zhou and Zhi Lu, 'Role of Tibetan Buddhist monasteries in snow leopard conservation', Conservation Biology (2014), pp. 87-94; Juan Li and Zhi Lu, 'Snow leopard poaching and trade in China, 2000-2013', Biological Conservation (2014) 174, pp. 207-211.

51 Makley, op. cit. (50), p. 251.

52 Shan Shui in Chinese is 山水. This literally translates as 'mountains and water', and is also a term used for a traditional style of landscape brush painting.

53 Interview with Charudutt Mishra, Bangalore, 15 March 2013, transcript on file with Michael Lewis. 
population and uses of the land. If conservation is to succeed, it must succeed both for human communities and for non-human nature.

Both Indian and Chinese actors have often critiqued the global conservation agenda as a proxy for a neo-imperialist West, ${ }^{54}$ and a casual survey of the role of the US-based and -founded SLT in India and China might seem to support the critique of cultural imperialism at play with snow leopard science. But as this history shows, snow leopard conservation biologists have not just been Westerners - the first significant article on snow leopards was by an Indian mountaineer, and Indian and Chinese scientists have played leadership roles in the Snow Leopard Trust and the Snow Leopard Network. When the SLT works in China, it does so through an Indian and a Chinese scientist Mishra and Lü Zhi. Mishra, who travels throughout Central Asia, India and China to check on various country programmes for the SLT, struggled to explain how his nationality matters when meeting other Asian scientists:

That SLT reputation precedes me ... but there is this ... it is difficult to explain exactly in words, but intuitively there is this 'Ah!' ... And I know that being an Indian we are able to relate at a level that might be difficult if I were, for instance, an American ... we have something in common. It is unwritten. It is never spoken about. ${ }^{55}$

Thus while American scientists such as George Schaller, Rodney Jackson, Joseph Fox and Tom McCarthy have clearly been pioneers in snow leopard science, and the SLT is based in Seattle, snow leopard conservation biology crosses borders almost as readily as the animal itself.

\section{Buddhism and snow leopard conservation biology, reprised}

One of the (now former) graduate students supervised by Lü, Mishra and Tom McCarthy is Li Juan, whose $2012 \mathrm{PhD}$ dissertation on wild snow leopards, 'Ecology and conservation strategy of snow leopard (Panthera uncia) in Sanjiangyuan Area on the Tibetan plateau', has been groundbreaking on a number of fronts. This research has been particularly transformative in terms of wildlife conservation approaches and as a basis for studying the ways that recent snow leopard research is having transnational impact through the efforts by Li Juan's research team to engage local Tibetan monasteries in conservation research and work. While this is not a novel idea (as noted above, Schaller himself proposed this as a future direction for conservation when he did snow leopard surveys in China during the 1980s), ${ }^{56}$ Li's dissertation reflects one of the most extensive and systematic implementations of such cooperation recorded thus far. ${ }^{57}$

Well before Li Juan began doing her research on snow leopards, other researchers working under Lü Zhi and her Shan Shui organization examined the notion of 'sacred sites' and their conservation potential. In an extensive study from 2004 to 2007

54 Perhaps none have done this more effectively than Ramachandra Guha.

55 Mishra interview, op. cit. (53).

56 Schaller, Ren and Qiu, op. cit. (24), p. 193.

57 Juan Li, op. cit. (3), pp. 78-83. 
they looked at 213 sacred mountains in Tibetan areas, which the authors say 'could have an important role in conservation ... because of strong local participation in conservation of sacred mountains'. ${ }^{58}$ Although very aware of this research and its potential, Li noted that the evolution of collaboration with the monasteries in conservation also developed 'naturally' in part because of the remarkable overlap between snow leopard habitat, sacred mountains and the presence of monasteries. ${ }^{59}$ Common aims exist between the conservation biologist's goal of protecting snow leopards and their habitat and the monastery's interest in protecting all life and the integrity of the sacred space; both seek protection of the wildlife and the mountain. The value biologists place on the snow leopard as a 'keystone species' is not shared in a parallel fashion by the Buddhists, who place emphasis on the equal value of all life. Yet nor are these concepts in conflict on a practical level.

As a result Lü Zhi and her students established a plan that included educating monks on scientific wildlife monitoring techniques and cultural outreach programmes in the form of posters that seek to appeal to the local population on the basis of Buddhist values. The poster reads, 'Beseeching the protection and preservation of the snow leopard, protector of the snow mountains' ${ }^{60}$ As made apparent in this poster, the collaboration is a recognition on the part of the scientists of the value of the religious and cultural significance of wildlife. Rather than trying to impose a scientific rationale for protecting the animals, they recognize that it would be much more effective to embrace the already extant culture and rationale for protecting wildlife in Buddhism and deferred to local rimpoche (religious teachers) to speak to local villagers about Buddhist teachings on the religious respect for life. ${ }^{61}$ The partnership is not without challenges, but it has great potential benefit, especially as the religious leaders in these monasteries hold great sway over local populations who might otherwise be participating in retaliatory killing for livestock loss.

The benefits of this interactive cooperation between biologists and monasteries in China's most remote upper reaches of the Tibetan plateau inspired their counterparts in India to pursue a similar programme. Mishra is well aware of this work - he is a co-author on Li's 2013 Conservation Biology paper (which also included Schaller and others) that focuses on the role of Buddhist monasteries in snow leopard conservation. ${ }^{62}$ Commenting on this work, Mishra pointed out,

We're learning from each other. In India, we had not always felt the need for interacting closely with Buddhist monasteries in snow leopard habitat. It was tricky for me, personally, in that I've thought of conservation as a more secular exercise. But in China, our team started to work with monasteries as a key partner, and later we started to do that in India. ${ }^{63}$

58 Shen Xiaoli, Lü Zhi, Li Shengzhi and Nyima Chen, 'Tibetan sacred sites: understanding the traditional management system, and its role in modern conservation', Ecology and Society (2012) 17(2), available at www.ecologyandsociety.org/vol17/iss2/art13.

59 Juan Li, op. cit. (3), p. 81.

60 Lobsang Norbu, translated from Tibetan, Tibetan Association of Northern California, 2015.

61 Juan Li et al., 'Role of Tibetan Buddhist monasteries, op. cit. (50).

62 Juan Li et al., 'Role of Tibetan Buddhist monasteries, op. cit. (50).

63 Mishra interview, op. cit. (53). 


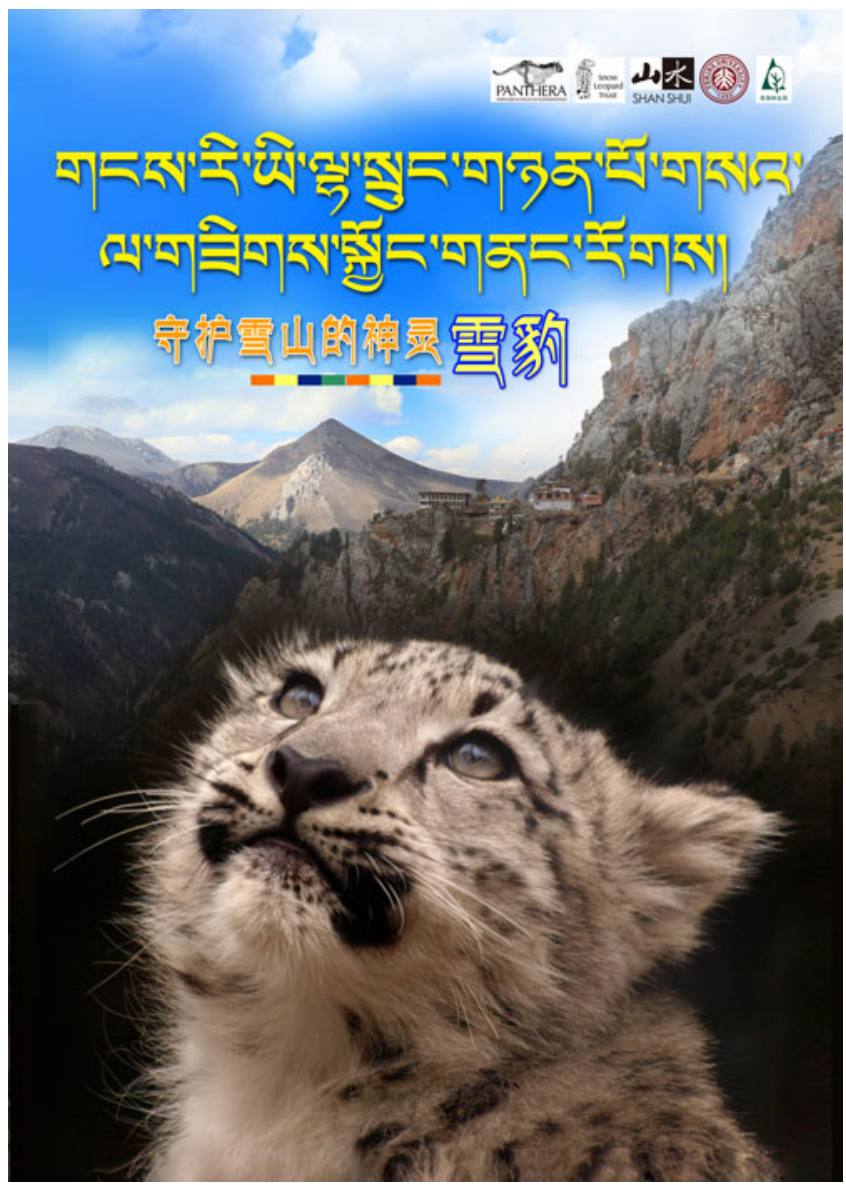

Figure 4. Poster used by researchers from Peking University for snow leopard protection outreach in Buddhist communities in the Sanjiangyuan National Nature Reserve area.

Initially the realization that scientists raised under the irreligious influence of the communist-based People's Republic of China would even be open to incorporating religious teachings in their approach to conservation, let alone promote it as a conservation technique, was surprising. That their practice of this approach would make scholars from India, known for its rich and diverse religious traditions, more comfortable with such an approach seemed ironic.

Precisely because religion (whether Hindu, Muslim, Christian, Buddhist or otherwise) has been central to various forms of political conflict in India, including the very founding of India and Pakistan as separate countries in 1947, many Indian biologists have steered clear of engaging with local people's religion as a tool for conservation. As Mishra points out, however, the model of the work done in China has shifted Indian practices, at least with snow leopards. They have developed their own posters, with 


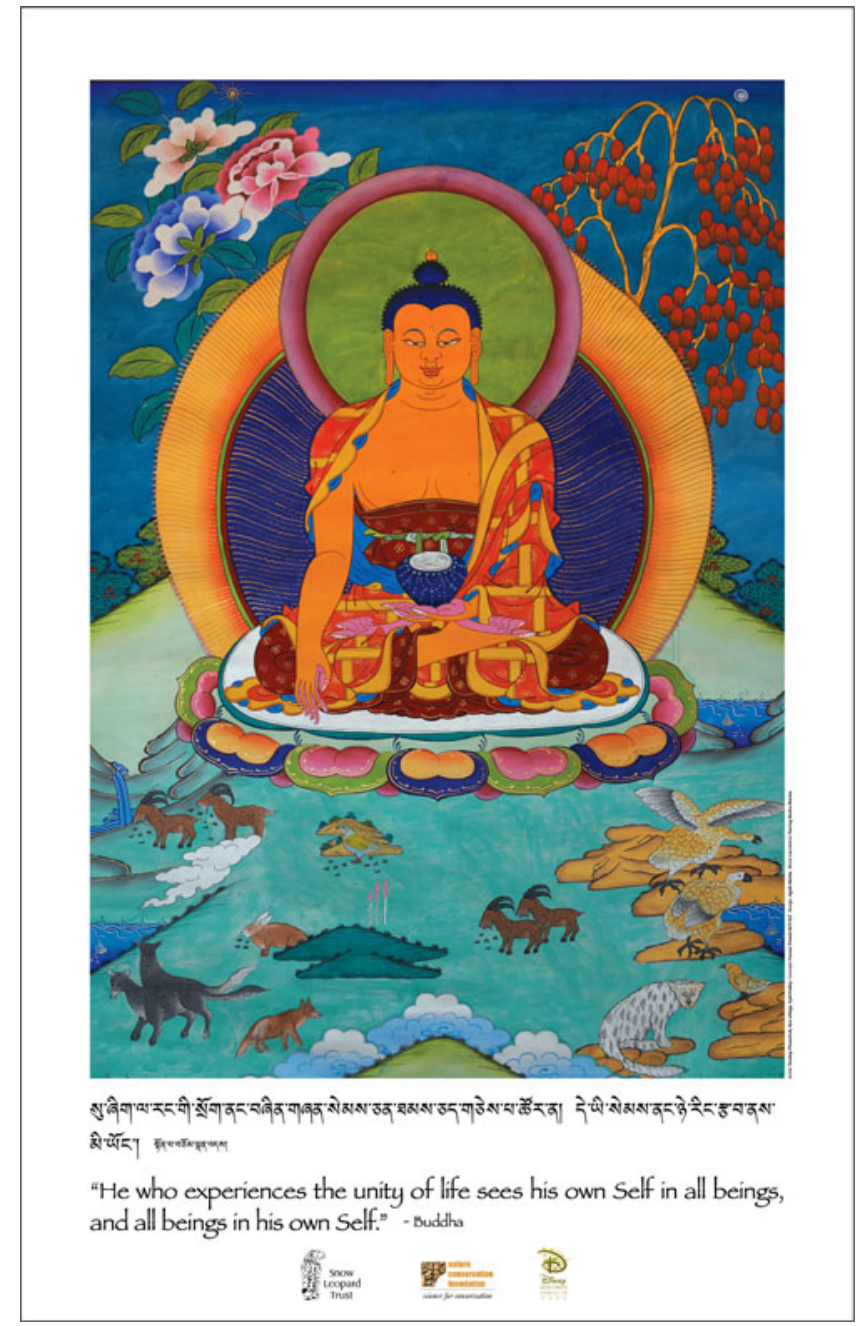

Figure 5. Poster used by researchers in India for snow leopard protection outreach in Himachal Pradesh.

quotes by the Dalai Lama and other monks, and as Bhatnagar, Mishra and others developed the Upper Spiti Landscape management plan with the government of Himachal Pradesh, they explicitly included this as a conservation tool. ${ }^{64}$ And perhaps this will extend even further beyond China and India? Conservation Biology is the leading global journal for the field, and the 2013 article by Li Juan and her colleagues is one

64 Bhatnagar and Mishra, op. cit. (44). 
measure of how the India-China snow leopard collaboration is impacting the scientific mainstream.

\section{Borderland conservation and the conservation of borders}

In spite of the successes of Indian and Chinese scientists in snow leopard research, national security has consistently trumped concerns about snow leopards - scientists are allowed access to the field only at the convenience of the state. And likewise, any conservation policies to protect snow leopards have been required to fit into geopolitical considerations. Researching and establishing conservation plans for the snow leopard are extremely challenging in part because its range spans the national borders of twelve countries, including some of the most troubled borders in the world. Coordinating surveys, studies and conservation-focused findings across all of these national boundaries is nearly impossible. One recent example attests to this: on 15 April 2013, Chinese soldiers walked ten kilometres beyond the line of control into the Indian state of Ladakh. The Chinese soldiers pitched tents and protested the construction of new Indian military facilities looking down upon crucial Chinese supply lines. In spite of some bellicose rhetoric in some sectors of the media, the Indian and Chinese governments carefully avoided escalating the conflict, and after some days of negotiations the Chinese returned to their side of the line of control, and India dismantled its forward station.

From the lens of snow leopard science, this highlights the difficulty faced by scientists attempting to study or conserve these animals. Stories such as these are omnipresent when field biologists in India gather around a cup of chai. They speak of permissions denied, of delays, of government suspicions about their work. In a small chai shop in Sikkim, in 2013, there was a WWF poster on the wall. This poster focused upon the key endangered species of the high trans-Himalayan cold desert, the snow leopard chief among them. The poster spoke of the threats to these animals - the usual suspects were there: poaching; habitat loss due to forestry, grazing or agriculture; conflict over domestic livestock loss. But then it included one other - landmines along the border. This poster, in a nutshell, encapsulated the uneasy status of conservation along troubled political borders.

In a region that is still fraught with so many military tensions, the chances of a scientist having free access for study, let alone a jointly managed conservation zone for high-altitude species, is slim indeed. Snow leopard researchers in China can avoid many of these problems by working hundreds of kilometres from the border, in Qinghai (as with Lü Zhi and Li Juan) or other less politically tense provinces. China has the largest snow leopard habitat in the world, and probably the highest population of snow leopards in the world, so this works, but at different points over the past forty years, thousands of square kilometres in TAR and Xinjiang have been largely off limits, or highly restricted, to snow leopard scientists. Thus there are limits to the completeness of scientists' knowledge of the status of snow leopards in China. Indian scientists have no options like Qinghai - all Indian snow leopard habitat is near the border with either 
Pakistan or China. Scientists working near these borders regularly have to get special permissions from the military - sometimes the Indian Army insists on sending soldiers with the scientists.

Intriguingly, this very liability has yielded interesting collaborations between scientists and the military within India. Project Snow Leopard included an explicit role for the armed forces, with representatives from the army and the Indo-Tibetan Border Police as permanent members of the PSL steering committee. Indian NGOs like the Nature Conservation Foundation and WWF-India have engaged with the armed forces in the Himalayas - increasing awareness of biodiversity and issues in conserving it, and searching for ways to constructively engage the military in conservation, as with the Tibetan gazelle in eastern Ladakh. In a recent essay by Bhatnagar and Mishra, they began by quoting a young army captain who had just returned from a posting in the world's highest battlefield, and who reported, 'We have abundant ibex and snow leopards near the Sianchen glacier. ${ }^{65}$ Scientists have conducted joint surveys with the Indian Army in Ladakh (2000) and Kashmir (2005). This again points to the way that the snow leopard's trans-border existence has led to scientists and conservationists crossing imagined borders. Collaborating with the military and police in this way is linked to the particularities of the snow leopard's range, just as was seen with the collaboration of scientists with Buddhist monasteries.

While it is perhaps to be expected that tense borderlands do not always yield ready conservation collaboration between states or between states and their scientists, more surprising is that while barriers theoretically should not exist within a country's conservation administrators or scientists, they do. In the case of giant pandas, one of the obstacles to collaboration among different bodies of research was that multiple administrative authorities of the government were involved in overseeing it, while with tigers, one Indian administrative unit was jealously protective of their prerogative to control all things connected with that animal. Although snow leopard research has not enjoyed the same government focus and popular recognition that propped up scientific studies of the giant panda or the tiger over the decades, snow leopard science faces some parallel challenges. Snow leopard research conducted by separate groups even within one country, as with China, is shared most often indirectly through journal publications. Independent studies conducted in research silos can result both in reinventing the wheel and in missed opportunities for conservation collaboration across the wide geographical expanse of this cat. Ironically, because the snow leopard is a trans-border animal, SLT has fostered an international apparatus that facilitates the communication between countries, which then also serves to foster communication within countries as well. This happens because the scholars from these separate groups convene in other countries and report about what is going on in their own country. So doing requires some recognition of each other's work.

This all suggests that not all animals are created equal, and that conservation biology is not monolithic in its relationship with state power. Pandas and tigers are privileged in conservation, because of the ease with which these species can be coopted by the state as

65 Bhatnagar and Mishra, op. cit. (44), p. 157. 
nationalist symbols, whereas the importance to the government of a species like the snow leopard that inhabits the borderlands is less obvious. This added difficulty in accessing governmental permission and funding makes researching a transnational animal like the snow leopard even more complex. Not surprisingly, then, snow leopard science is trending in quite a different direction than scientific research on tigers or pandas.

Perhaps because of the lack of nationalist rhetoric surrounding snow leopard conservation, and the relative lack of state investment in its continued existence over the last forty years, scientists working on high-altitude ecology have been leading their peers within conservation biology in rethinking conservation strategies without starting with the state. In the absence of a strong state interest in conservation of the snow leopard, and given the unique ecological features of the high Himalayas, scientists had to consider ways to make conservation work beyond just protected areas, and on a local scale. This occurred by conceptualizing large-scale landscape conservation plans with villages and human uses embedded in the conservation matrix, and working with local villagers through their religious practices and beliefs. In sum, this has meant that snow leopard scientists tend to be far less top-down than, for instance, scientists working in India on tigers or in China on giant pandas. However, as seen with Project Snow Leopard, they have worked hard to get government officials to accept this landscape conservation model. As Bhatnagar wrote, 'I have no illusions of succeeding [in conserving snow leopards] in landscapes spanning many thousand square kilometers with minimal government involvement.' 66 The scale of conservation needed is vast, and to succeed in the long term there must be state buy-in. And the role of the state, then, is to create, monitor and enforce a legal framework that allows for fluid, local and improvisational solutions across the wider high-altitude landscape.

There is one additional role in snow leopard conservation for the state that has emerged over the past year. Following a period of intense preparation by a range of NGOs, including prominently the SLT and Mishra, on 23 October 2013 leaders from the governments of all twelve states that hold wild snow leopard populations agreed to the Bishkek Declaration. This was the outcome of a two-day conference that provided the start for the Global Snow Leopard \& Ecosystem Protection Program (GSLEP). With support from the World Bank, UNDP, SLT, WWF, US-AID and others, the GSLEP proposed a seven-year commitment by the twelve nations to a series of actions promoting snow leopard conservation. A secretariat was established in Bishkek (capital of Kyrgyzstan) to oversee this programme. At its most basic level, the GSLEP proposes guaranteeing twenty secure wild breeding populations of at least a hundred snow leopards by the year 2020. Their mission statement explains in more detail that these secure landscapes must be conserved 'with the involvement of local communities', and 'have functional connectivity to other snow leopard landscapes, some of which cross international boundaries'. GSLEP announced an ultimate goal of 'ensuring that snow leopards remain the living icon of mountains of Asia for generations to come' ${ }^{67}$

66 Bhatnagar, personal communication.

67 'Global snow leopard \& ecosystem protection program: who we are', www.globalsnowleopard.org/ who-we-are/gslep-program, accessed 29 December 2015. 
Here we see the snow leopard not as a national icon, but as a symbol for an entire region - the mountains of Asia - and the conservation initiative not proposed by a national government, but as an international initiative. While none of the participating states are interested in eliminating borders, they do recognize that snow leopards cross them. The National Snow Leopard and Ecosystems Priorities documents that were created by the twelve participating states exhibit a strong debt to the landscape conservation proposals of the snow leopard science conducted in China and India over the past decades, and particularly the role of conservation embedded in communities. The India national plan is strongly related to Project Snow Leopard, and the priorities of the GSLEP are in many ways that proposal writ large.

Perhaps historians of the twenty-first century will write of a very different sort of conservation biology emerging out of the twentieth century, of animals no longer just as symbols of the unitary state, but animals conserved and cherished as symbols of the transnational ties that bind us. And if so, why not the snow leopard as a key example? The GSLEP seems like a step in this direction. But this continues to be a serious challenge in a world where states still struggle to control this fluidity and where nationalism often trumps hybridity in media and politics. 